\title{
Small Signal Stability Assessment in Presence of SSSC for a Power System Under Fault Disturbance
}

\author{
Rupali Brahmachary and Dipu Sarkar*
}

\begin{abstract}
The use of FACTS controllers in power grids has resulted in the improvement of stability issues related to the power systems. When the FACTS controllers are used to damp out the power systems oscillation, there series controller inverter like static synchronous series compensator (SSSC) device are the most suitable to resolve the issue. In this paper, importance is given on the optimal operation of the SSSC and to the maintenance of the small signal stability of the system. Here the main focus is to check the system response to stability after the use of SSSC device.
\end{abstract}

Index Terms: static synchronous series compensator, voltage source inverter, small signal stability, power flow, eigen value analysis, power transmission.

\section{INTRODUCTION}

A mong the modern FACTS devices falls the Static Synchronous Series Compensator (SSSC), which is coupled in series with the transmission line along with the help of a coupling transformer. The SSSC device works like a series capacitor and inductor, but the injected voltage is independent of the line intensity, thus SSSC works with both high and low loads satisfactorily. When SSSC works with appropriate supply it can introduce voltage component which is similar to the voltage across the line but the phase angle is opposite to that of the line voltage angle. It is usually used to mitigate the voltage required during fault condition in the power system. The other advantages of using SSSC devices includes power factor correction, load balancing of the interconnected distributed networks, helps in covering capacitive and reactive power demands, also helps in controlling power flow and lastly actively filtering the harmonic distortion.

Manuscript received August 20, 2020; revised September 10, 2020; accepted April 15, 2021.

Rupali Brahmachary and is with National Institute of Technology, Nagaland, India (e-mail: brahmachary.rupali29@gmail.com).

Dipu Sarkar is with National Institute of Technology, Dimapur-797103, Nagaland, India (e-mail: dipusarkar5@ rediffmail.com).

*Corresponding author.

\section{LITERATURE REVIEW}

A SSSC is a voltage source inverter, which together with a transformer is linked with the transmission line in series connection. The injected voltage is almost in quadrature with the line current of the transmission line, paper [1], and thus helps in reducing the capacitive or inductive effect of the line, but in-turn affecting the power flow of the transmission line. Paper [2] deals with the reactive power compensation and voltage stabilization of the electric grid using SSSC. Performance of SSSC is evaluated when it is connected to $230 \mathrm{kV}$ grid network. The SSSC is relatively one of the recent inventions in FACTS devices, it is coupled in series with transmission grid along with a coupling transformer and it helps in regulating the active and reactive power of the transmission line; paper [3], it also helps in controlling bus voltage. The operation and dynamic enactment of SSSC in transmission system is taken consideration in paper [4] and a secondary regulator is suggested so as to control the dynamic performance and the inherent delays. Constant reactance mode and constant quadrature voltage mode are the ways of regulating the degree of the series compensation provided by the SSSC device. Paper [5] emphasizes on damping power and synchronizing power of the supposed radial power system. The static voltage enhancement is being checked using the different FACTS devices by doing power flow simulation and assessing static voltage stability in paper [6]. SSSCs are integrated to the network in a linear design and the damping control function is investigated, the investigation considers both multi-machine power system and single machine infinite bus as in paper [7] to study the properties of SSSC. A Multi-objective optimization technique is used in paper [8] to study the scheme of SSSC in order to increase the transient performance of the entire system under consideration when exposed to severe disturbance by damping the oscillations. The SSSC has dielectric capacitors which helps in lowering the cost of series compensation as explained in paper [9], the capacitor has a resonating frequency equal to the line inductance and thus it balances and cancels out the torsional resonance of the shaft of the steam turbine. The different SSSC control modes which includes constant voltage, constant impedance and constant power modes are taken into consideration and their impact on the power system has been studied in paper [10]. The performance with different input signal on all these three control modes and power oscillation damping regulator is assessed. SSSC based damper is used in paper [11] to study the improvement of network's stability including both remote signals and local signals with the time interruptions related with them. Differential algorithm is used to examine 
the optimal controller parameters. Stability performance of the system is improved when the SSSC based damping controller is used to lessen the time-domain based objective function as explained in paper [12]. The derivative of oscillatory rotor speed of the generator is involved and it is damped out using the SSSC device.

The key objective of this paper is checking the stability and system response of the network after the FACTS device is used. Here the Eigen value analysis is done in order to evaluate the small signal stability of the given network.

\section{A. Theoretical Background}

The real power and reactive power of a simple transmission link having reactance $X_{\mathrm{L}}$, sending end voltage $\mathrm{V}_{\mathrm{S}}$ and receiving end voltage $V_{\mathrm{R}}$ is given by equation (1) and (2) respectively.

$$
\begin{aligned}
& P=\frac{V_{S} V_{R}}{X_{L}} \sin \delta \\
& Q=\frac{V_{S} V_{R}}{X_{L}}(1-\cos \delta)
\end{aligned}
$$

The receiving end real and reactive power equations is given by equation (3) and (4) respectively:

$$
P=\frac{V_{S} V_{R}}{X_{L}} \sin \left(\delta_{S}-\delta_{R}\right)=\frac{V^{2}}{X_{L}} \sin \delta
$$

and

$$
Q=\frac{V_{S} V_{R}}{X_{L}}\left(1-\cos \left(\delta_{S}-\delta_{R}\right)=\frac{V^{2}}{X_{L}}(1-\cos \delta)\right.
$$

A SSSC is capable of competing the transmission line inductive reactance $X_{\mathrm{L}}$ by the help of its compensating reactance $X_{\mathrm{q}}$. Therefore, the expression for Power flow gets modified into the following equations:

$$
P_{q}=\frac{V^{2}}{X_{e f f}} \sin \delta=\frac{V^{2}}{X_{L}\left(1-\frac{X_{q}}{X_{L}}\right)} \sin \delta
$$

and

$$
Q_{q}=\frac{V^{2}}{X_{e f f}}(1-\cos \delta)=\frac{V^{2}}{X_{L}\left(1-\frac{X_{q}}{X_{L}}\right)}(1-\cos \delta)
$$

where, $X_{\text {eff }}$ is the effective resistance of the transmission line between the two ends including the SSSC induces variable reactance of the voltage source. The $X_{\mathrm{q}}$ is positive when the SSSC device is operated in the capacitive mode and negative when the SSSC is operated in inductive mode.

\section{B. Small Signal Stability}

Small signal stability analysis emphasizes on the stability issues when the given system is subjected to small perturbation, it can be defined as the system's ability to remain in the stable condition after suffering a small disturbance for a prolonged time, which might lead to a small deviation in the system's state variables. The Eigen values of the system can be analyzed by performing small signal stability on a system. The differential algebraic equation of the system is in the form:

$$
\begin{aligned}
& x_{s}=f_{\mathrm{s}}(x, y) \\
& 0=g_{\mathrm{s}}(x, y)
\end{aligned}
$$

where $x$ is the system's state variable vector representing the magnitude of voltage, $y$ is the algebraic variable vector representing the phase angle. Thus, the entire state matrix is obtained from computing the Jacobian matrix. In order to reduce the computational analysis the Jacobian matrix is reduced by fast decoupled load flow analysis method to the reduced Jacobian matrix giving the equation as:

$$
J_{R}=F_{x}-F_{y} G_{y}^{-1} G_{x}
$$

The reduced jacobian matrix is then used to find out the Eigen values of the system by the equation:

$$
E_{S}=\varphi J_{R}
$$

where $\varphi$ is the Eigen vector matrix.

Equation (10) gives valuable information about the relative values of the voltage stability.

\section{RESUlt AND SIMULATION}

The IEEE-14 Bus test system consists of 16 transmission line, 5 Generator, 1 slack bus, and 11 loads. The base MVA is $100 \mathrm{MVA}$ and base $\mathrm{KV}$ is $69 \mathrm{KV}$. There is a fault at bus number 5 at the base case, as shown in Fig. 1.

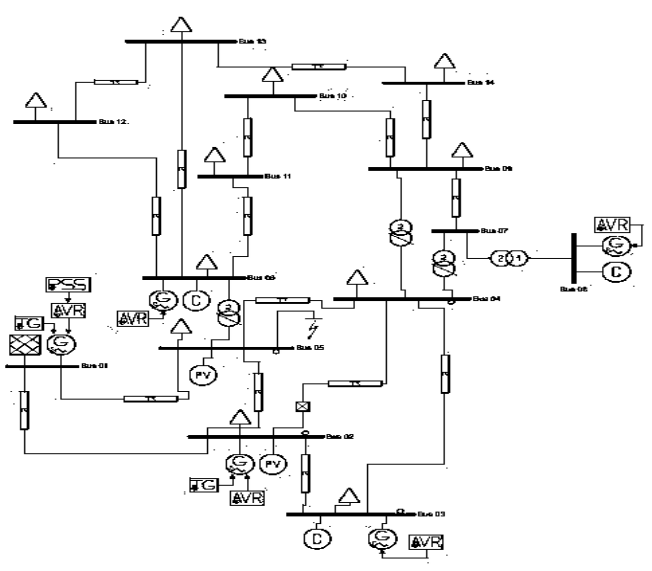

Fig. 1. IEEE-14 Bus system in faulted condition.

The fault is LLLG occurring at bus 5, having real power loss equal to $31.8846 \mathrm{MW}$ and reactive power loss is 98.8011 MVar. In order to improve the system response occurred in the fault condition, SSSC is connected between bus 02 and bus 05, as shown in Fig. 2.

In this system two cases are considered. In case 1, the fault condition is considered and in case 2, SSSC FACTS device is used to improve the condition created in the system due to the LLLG fault. The SSSC is used here to improve the transmission property of the system in consideration.

Table I. Consists of the comparison of the power flow case study. The generated real power in faulted condition is 394.4846 MW but after the use of SSSC the real power is reduced to 388.2467 MW. Similarly, the reactive power 
during the faulted condition is 212.7611 MVar but after the SSSC device is used the reactive power is reduced to 199.3778 MVar.

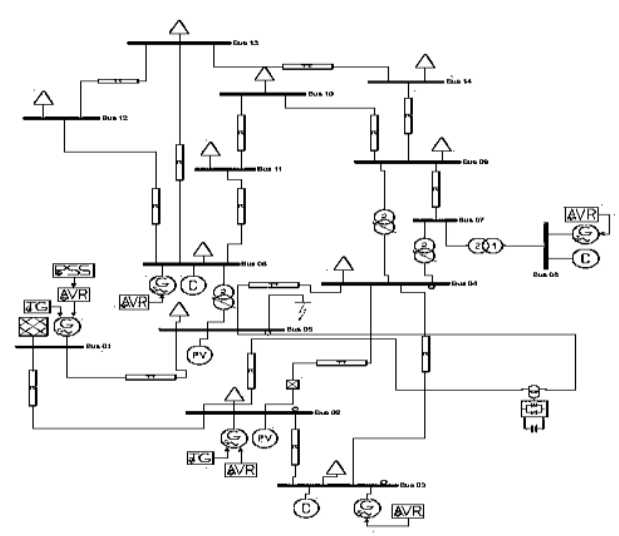

Fig. 2. IEEE-14 Bus system with SSSC.

TABLE I. POWER FLOW RESUlt COMPARATION

\begin{tabular}{lcc}
\hline & Fault & SSSC \\
\hline Total Generation & & \\
\hline Real Power [MW] & 394.4846 & 388.2467 \\
Reactive Power [MVAr] & 212.7611 & 199.3778 \\
\hline Total Load & & \\
\hline Real Power [MW] & 362.60 & 362.60 \\
Reactive Power [MVAr] & 113.96 & 113.96 \\
\hline Total Losses & & \\
\hline Real Power [MW] & 31.8846 & 25.6467 \\
Reactive Power [MVAr] & 98.8011 & 85.4178 \\
\hline
\end{tabular}

Again, while considering the losses, the real and reactive power of the system during faulted condition is $31.8846 \mathrm{MW}$ and 98.8011 MVar respectively, which after the use of SSSC has reduced to 25.6467 MW and 85.4178 MVar respectively. The results clearly show an improvement after the use of SSSC devices

Table II shows the comparison of Eigen value analysis. It is seen that the dynamic order of the system has increased from 58 to 59 , showing the system after the use of SSSC gains a more stable position.

TABLE II. COMPARISON OF EIGEN VALUE

\begin{tabular}{lcc}
\hline & Fault & SSSC \\
\hline Dynamic Order & 58 & 59 \\
\hline Number of Negative Eigen Values & 55 & 56 \\
\hline Number of Positive Eigen Values & 2 & 2 \\
\hline Number of Real Eigen Values & 30 & 31 \\
\hline Number of Complex Pairs & 14 & 14 \\
\hline Number of Zero Pairs & 1 & 1 \\
\hline
\end{tabular}

Again, the number of negative Eigen values has increased from 55 (when the system experiencing LLLG fault condition) to 56 (after the use of SSSC) and the number of real Eigen Values has also increased from 30 to 31, as seen in Table II, further the emphasizing the fact that the stability of the system has improved.

Figure 3 and Fig. 4 give the Eigenvalue positions at the faulted system condition and after using SSSC device respectively.

Comparing Fig. 3 and Fig. 4, an improvement is seen in the location of the Eigen values after the use of SSSC, inferring that the small signal stability of the system is improving after the use of the SSSC, as the Eigen values shifts more towards the stability region

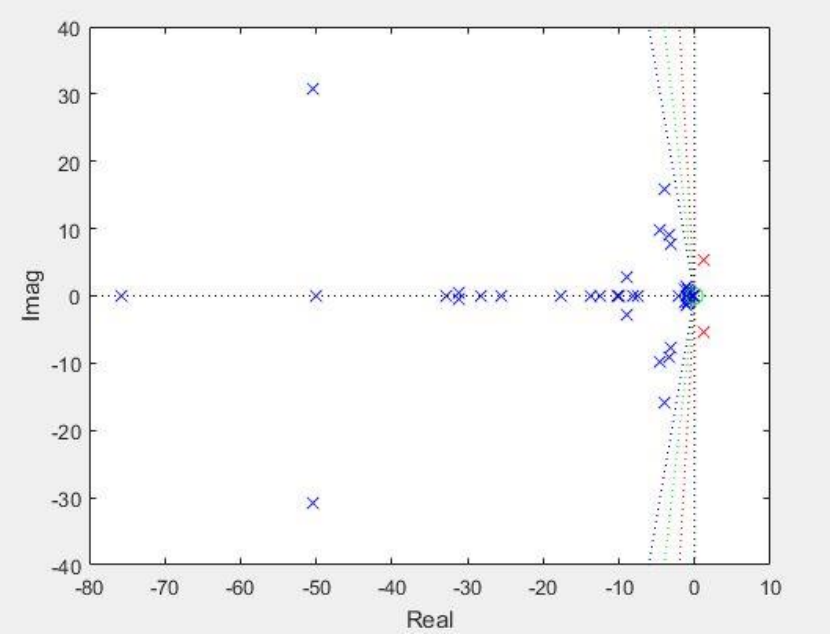

Fig. 3. Eigen Value Position in faulted condition.

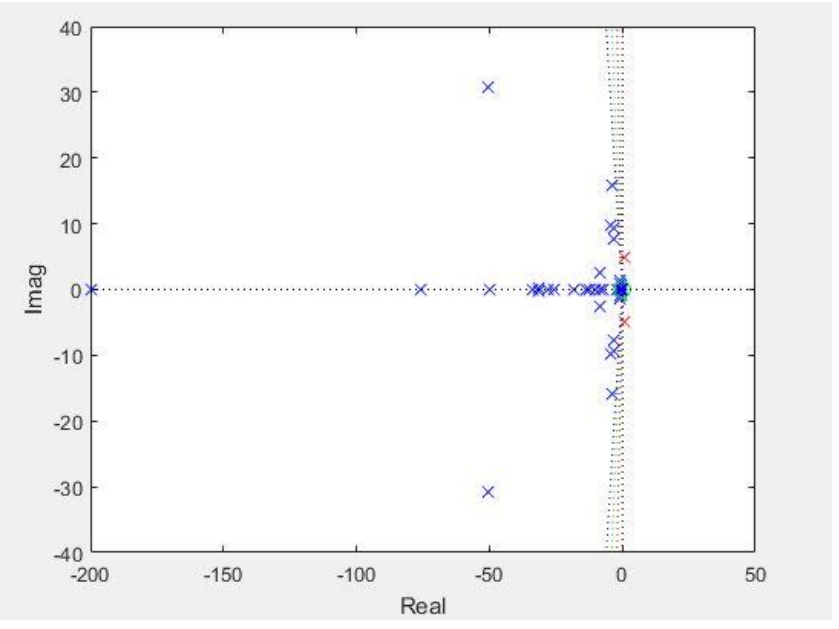

Fig. 4. Eigen Value Position in faulted condition.

\section{CONCLUSION}

It can be concluded that the system has shown an improved study after the use of SSSC FACTS device in terms of system response to the small signal stability of the system.

\section{REFERENCES}

[1] Sen, K.K., "SSSC-static synchronous series compensator: theory, modeling, and application," IEEE Transactions on power delivery, vol. 13, no. 1, pp. 241-246, 1998

[2] El-Moursi, M. S., and A. M. Shara, "Novel controllers for the 48-pulse VSC STATCOM and SSSC for voltage regulation and reactive power compensation," IEEE Transactions on Power systems, vol. 20, no. 4, pp. 1985-1997, 2005.

[3] Zhang, X.P., "Advanced modeling of the multicontrol functional static synchronous series compensator (SSSC) in Newton power flow," IEEE Transactions on Power Systems, vol. 18, no. 4, pp. 1410-1416, 2003. 
[4] Norouzi, Amir H., and A. M. Sharaf, "Two control schemes to enhance the dynamic performance of the STATCOM and SSSC," IEEE Transactions on Power delivery, vol. 20, no. 1, pp. 435-442, 2005.

[5] Jowder, Fawzi AL, "Influence of mode of operation of the SSSC on the small disturbance and transient stability of a radial power system." IEEE Transactions on Power Systems 20, no. 2 (2005): 935-942.

[6] Sode-Yome, Arthit, Nadarajah Mithulananthan, and Kwang Y. Lee, "Static voltage stability margin enhancement using STATCOM, TCSC and SSSC," In 2005 IEEE/PES Transmission \& Distribution Conference \& Exposition: Asia and Pacific, pp. 1-6, 2005.

[7] Wang, H. F, "Design of SSSC damping controller to improve power system oscillation stability," In 1999 IEEE Africon. 5th Africon Conference in Africa (Cat. No. 99CH36342), vol. 1, pp. 495-500. IEEE, 1999.

[8] Panda, Sidhartha, "Multi-objective evolutionary algorithm for SSSC-based controller design." Electric Power Systems Research, vol. 79, no. 6, pp. 937-944, 2009.

[9] Jowder, F. A. R. A., and Boon-Teck Ooi, "Series compensation of radial power system by a combination of SSSC and dielectric capacitors," IEEE Transactions on Power Delivery, vol. 20, no. 1, pp. 458-465, 2005.

[10] Castro, M.S., Ayres, H.M., Da Costa, V.F. and Da Silva, L.C.P., "Impacts of the SSSC control modes on small-signal and transient stability of a power system," Electric power systems research, vol. 77, no. 1, pp.1-9, 2007.

[11] Panda, Sidhartha, "Differential evolution algorithm for SSSCbased damping controller design considering time delay," Journal of the Franklin Institute, vol. 348, no. 8, pp. 1903-1926, 2011.
[12] Panda, Sidhartha, N. P. Padhy, and R. N. Patel, "Power-system stability improvement by PSO optimized SSSC-based damping controller," Electric Power Components and Systems, vol. 36, no. 5, pp. 468-490, 2008.

\section{BIOGRAPHIES}

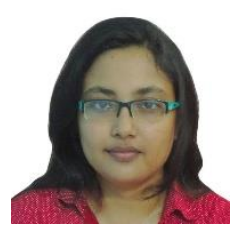

Rupali Brahmachary did her B. Tech in Electrical Engineering in 2018 and has completed her M. Tech degree in Power System Engineering from National Institute of Technology, Nagaland in 2020 and presently pursuing $\mathrm{Ph}$. D program from National Institute of Technology, Durgapur, India. Her research interests include Congestion management in deregulated environment, Stability analysis of deregulated system under congested condition. Currently her research work focuses on EVs.

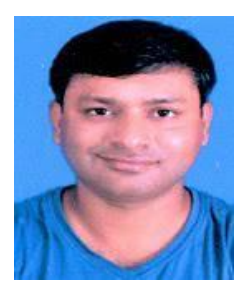

Dipu Sarkar received his B. Tech. in Electrical Engineering in 2003 from University of Kalyani, W. B., India, $\mathrm{He}$ received his $\mathrm{M}$. Tech. with specialization of electrical power systems from University of Calcutta, India in 2007 and his $\mathrm{Ph}, \mathrm{D}$ degree from the Department of Electrical Engineering, Bengal Engineering and Science University, Shibpur, India (presently known as Indian Institute of Engineering Science and Technology, IIEST) in 2013. Currently, he is an assistant professor in the Department of Electrical and Electronics Engineering of National Institute of Technology, Nagaland, India. His fields of interest are power systems operation and control, power systems stability, soft computational applications in power systems and smart grids, grid integrated renewable energy, service restoration and protective relay coordination. 